\title{
Modeling of smart concrete beams with Shape Memory Alloy actuators
}

\author{
S. Malagisi, S. Marfia, E. Sacco \\ DiCeM, Department of Civil and Mechanical Engineering, University of Cassino and Southern Lazio, Italy \\ s.malagisi@unicas.it,marfia@unicas.it,sacco@unicas.it \\ J. Toti \\ Department of Civil, Construction-Architectural and Environmental Engineering, University of L'Aquila, Italy \\ jessica.toti@unicas.it
}

\begin{abstract}
In the present work, a computational strategy for the modeling of reinforced concrete beams with shape memory alloy (SMA) actuators for flexural cracks repair is developed. In particular, for the concrete, a nonlocal damage and plasticity model is adopted; the model is able to consider peculiar macroscopic behaviors which characterize the quasi-brittle materials, such as the tensile and compressive damaging, accumulation of irreversible strains and the unilateral phenomena. The development of the flexural cracks in concrete are modeled using the cohesive zone interface formulation, which accounts for the mode I, mode II and mixed mode of damage, the unilateral contact and the friction effects. The interface model considers even the coupling between the body damage and the interface damage ensuring that body damage and interface damage cannot evolve independently one from the other. A uniaxial SMA model able to reproduce both the pseudo-elastic behavior and the shape memory effect is adopted for the reinforcing SMA wires.

Finally, finite element simulations are developed in order to reproduce the experimental behavior of smart concrete beams subjected to three-point bending tests.
\end{abstract}

SOMMARIO. Nel presente lavoro è sviluppata una strategia computazionale per la modellazione di travi in calcestruzzo rinforzate con attuatori in materiale a memoria di forma (SMA) per la riparazione delle fessure flessionali. In particolare, per il calcestruzzo, si adotta il modello di danno non locale in grado di riprodurre le caratteristiche principali del comportamento macroscopico dei materiali quasi-fragili, come il danneggiamento in trazione e in compressione, l'accumulo di deformazioni plastiche e il fenomeno unilatero di richiusura delle micro-fessure da danno. La formazione delle fessure nel calcestruzzo è modellata usando la formulazione di un'interfaccia coesiva, che considera il danneggiamento in modo I, in modo II e in modo misto, il fenomeno dovuto al contatto unilatero e all'attrito. Il modello di interfaccia considera anche l'accoppiamento tra il danneggiamento del corpo e quello dell'interfaccia, assicurando che il danneggiamento del corpo e dell'interfaccia non evolvono indipendentemente l'uno dall'altro. Un modello uniassiale SMA capace di riprodurre sia l' effetto pseudo-elastico che quello a memoria di forma è utilizzato per i fili SMA.

Infine, sono sviluppate simulazioni agli elementi finiti per riprodurre il comportamento sperimentale di travi in calcestruzzo intelligente sottoposte a prove di flessione su tre punti.

KEYwORDS. Smart Concrete; Shape Memory Alloy; Damage. 


\section{INTRODUCTION}

I $\mathrm{n}$ recent years smart materials technology has become an area of increasing interest also in civil engineering. Smart materials are multifunctional materials thought to execute other functions in addition to the structural one. In civil engineering, smart materials applications concern mainly smart concrete obtained adding special materials or devices to the traditional concrete. A particular type of smart concrete, widely studied and experimentally investigated, is the smart concrete obtained adding Shape Memory Alloy (SMA) bars. This kind of smart concrete can be used to allow the repairing or the self-repairing of concrete structural elements. Particular attention is paid to this kind of applications because they improve the durability of structural elements.

Concrete is a widely used structural material characterized by a low tensile strength. Reinforced concrete combines the good compressive response of the concrete with the tensile capacity of reinforcing steel bars. In this way the structural element is able to carry compression, bending and shearing forces. However, in these types of structural elements cracks are unavoidable. Diffuse and deep cracks are very dangerous for the durability and mechanical capacity of the element. In fact, because of the development of cracks, the steel reinforcing bars are subjected to the oxidation process which leads to reduce the steel net area.

The damage and cracks repairing, the improvement of the mechanical proprieties and the water tightness regaining can ensure the safety and reliability of the structural system, which are essential for large scale structures when they are still in service.

Hence, the development of smart concrete technologies, assuring the repairing of the damage and cracks in real time, has become a very important research topic. Experimental campaigns [1 - 3] and theoretical and numerical researches have been rapidly performed in recent years. In particular, the special composite structural system, constituted by reinforced concrete with SMA wires embedded, exhibits a behavior highly nonlinear and, as consequence, complex to simulate.

In the present work, a new computational strategy for the modeling of reinforced concrete beams with SMA actuators for flexural cracks repair is proposed. In particular, the nonlocal damage and plasticity model proposed in [5] is adopted for the concrete; the model is able to consider the specific macroscopic behaviors which characterize the quasi-brittle materials, such as the tensile and compressive damaging, accumulation of irreversible strains and the unilateral phenomena. The development of the flexural cracks in concrete are modeled using the cohesive zone interface formulation, which accounts for the mode I, mode II and mixed mode of damage, the unilateral contact and the friction effects. The interface model also considers the coupling between the body damage and the interface damage ensuring that body damage and interface damage cannot evolve independently one from the other $[4,5]$. Both the pseudo-elastic behavior and the shape memory effect of SMA wires are reproduced using the model presented in [6].

Finite element simulations are developed in order to reproduce the experimental behavior of smart concrete beams subjected to three-point bending tests [1].

\section{CASE OF STUDY}

he experimental campaign carried out by Daghia et al. [1] concerns the study of the behavior of a small scale smart concrete beam subjected to three-point bending test.

The geometry of the tested beam is schematically reported in Fig. 1. The beam has $80 \times 100 \mathrm{~mm}^{2}$ rectangular cross section and a length of $500 \mathrm{~mm}$. The traditional reinforcement is characterized three steel bars of $4 \mathrm{~mm}$ of diameter.
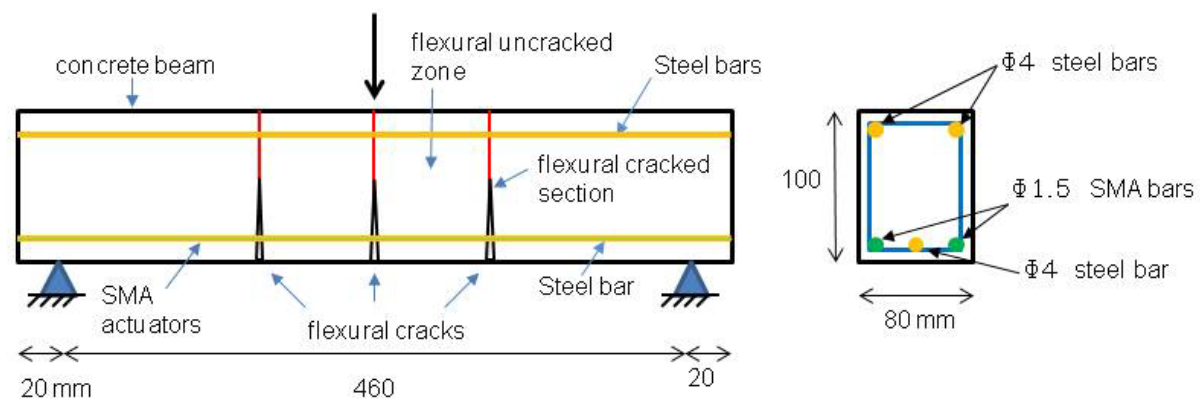

Figure 1: Schematic representation of reinforced concrete beam with SMA actuators. 
The reinforced beam is built in two phases:

- the SMA wires are prestrained at 5.8\%, allowing the transformation from austenite to martensite; then, the prestrain load is removed in order to recover the elastic deformation.

- the beam is manufactured using rheoplastic mortar Emaco S33 produced by BASF, having the maximum size of the aggregates less than $10 \mathrm{~mm}$, which is suitable for a small scale beam.

The experimental three-point bending test is performed using a testing machine characterized by a distance between the supports of $460 \mathrm{~mm}$.

The experimental test consists of three phases. In the first phase, the beam is loaded up in order to obtain the formation of cracks and the increasing of their width; in the second phase, the beam is unloaded; in the third phase, the SMA elements are actuated heating up the wires via Joule effect. In particular, during this last phase the cracks closure and the reduction of the residual beam deflection are observed (Fig. 2).

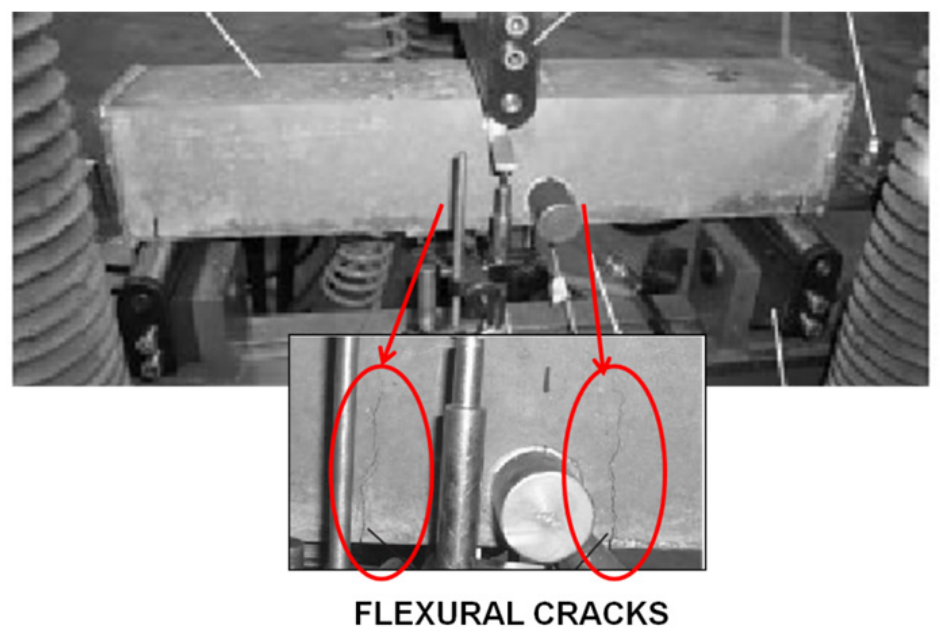

Figure 2: Flexural cracks observed during the experimental test.

\section{MODELING}

I

$\mathrm{n}$ this section the modeling of reinforced concrete beam with SMA actuators for flexural cracks repair is presented.

For the structural scheme investigated during the experimental campaign [1], the two-dimensional modeling reported

in Fig. 1, is considered. In particular, the structural modeling consists in considering:

- the damaging and plastic model for the concrete;

- the cohesive interface model for considering the potentially cracked concrete cross-sections, i.e. areas where the tensile damaging tends to localize and the flexural cracks to open. The number and the distance between the interfaces is determined a priori thanks to a pre-analysis. The propagation of the flexural cracks is assumed to be influenced by the damaging of the concrete;

- uniaxial SMA model for the wires, which takes into account both pseudo-elastic effect and the shape memory behavior;

- Mises plasticity model for the reinforcing steel bars.

Perfect adhesion hypothesis is assumed both between the concrete and the SMA wires interface and between the concrete and the steel bar interface.

The main aspects characterizing the adopted models are briefly described in the following.

The nonlinear behavior of the concrete is simulated considering the cohesive model recently proposed by Toti et al. [5]. The model is able to reproduce two important characteristic behaviors observed at the macroscale under cyclic loadings: degradation of the mechanical properties (damage) and accumulation of irreversible strains (plasticity). The model considers even the stiffness recovery and loss due to crack closing and reopening by introducing two scalar damage variables: a tensile and a compressive damage parameter. Moreover, it is assumed that the damage occurring in compression directly induces damage in tension; in other word the damage in tension results always not lower than the damage in compression. In particular, the evolution of the compressive damage depends on the nonlocal measure of the 
accumulation of the plastic strain, while the growth of the tensile damage is governed by the nonlocal value of the equivalent elastic strain or by the nonlocal measure of the accumulation of the plastic strain. The plastic flow is controlled by the effective stress through the introduction of a hyperbolic yield function, representing a branch of a modified hyperbola. The plastic-nonlocal model is able to capture the size effects and avoid spurious localization which gives rise to pathological mesh sensitivity in numerical computations.

For the flexural crack concrete cross-sections, an interface model based on a cohesive zone formulation and on a coupling law, combining body and interface damage, is introduced [4, 5]. In particular, the cohesive zone model is able to consider the unilateral contact behavior, interface damaging and friction phenomenon. The loss of cohesion at the interface is described by introducing a scalar damage variable, which is controlled by the relative interface displacement in reproducing the Mode I, Mode II and by the mixed mode. The coupling law is developed on the basis of a micromechanical idea introducing a Representative Elementary Area (REA) of interface.

The SMA behavior is reproduced using the model proposed by Marfia et al. [6]. The model reproduces the pseudo-elastic behavior as well as the shape memory effect; in particular, the analysis is restricted to the case in which the temperature is greater than martensite start temperature. Thus, only austenite - single variant martensite and single variant martensite austenite transformations are considered. In the formulation of the model the single variant martensite volume fraction is chosen as independent internal variable governing the phase transformations. The model takes into account the different behavior in tension and in compression of the SMA.

The described models are implemented in a research version the finite element code FEAP [7]. The finite element discretization of the beam is reported in Fig. 3. Because of the symmetry of the problem only half part of the beam is modeled by using suitable boundary conditions. In particular, four nodes quadrilateral elements are adopted to model the flexural uncracked concrete, four nodes interface elements are used to model potentially flexural cracked cross-sections, beam elements and truss elements are adopted to reproduce the behavior of the equivalent SMA bar and of the steel bar, respectively.

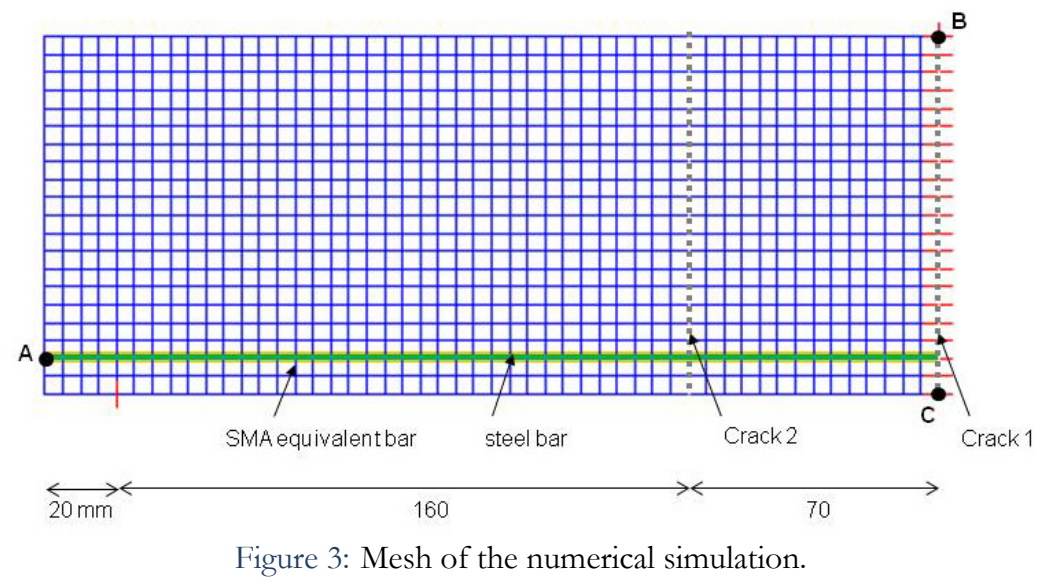

In Tab. 1 - 4, the mechanical proprieties assumed, for the concrete elements, the interface elements, the SMA elements and the steel elements, are reported, respectively.

The steel reinforcement in compression is not considered in the numerical simulations because the overall response of the reinforced beam is not strongly influenced by the presence of the steel bars in compression.

All four nodes nonlocal damage and plasticity quadrilateral elements have same dimensions; they are square elements of size $5 \mathrm{~mm}$. The length of steel and SMA elements is also about $5 \mathrm{~mm}$, only the elements which cross the cracks are characterized by a length of $10 \mathrm{~mm}$. This choice is adopted to reproduce the not perfect adhesion between SMA bars and concrete and between steel bar and concrete in the sections near the cracks. The nodes of steel elements coincide with nodes of concrete elements.

To define SMA elements new nodes are generated, which have the same coordinates of the nodes of steel and concrete elements.

In Tab. 5, the loading history adopted to simulate the building phase and the experimental test are illustrated. In particular:

- in phase 0 , the prestrain and the release of the SMA equivalent bar, at the environmental temperature, are reproduced. This phase is made up of two time steps: in time step 0-1 SMA, equivalent bar is prestrained at 5.8\% imposing an axial displacement $w_{A}$ of the node A of the SMA bar, in time step 1-2, the bar is unloaded controlling 
the axial displacement $w_{A}$ of the node A. During phase 0 , the SMA elements are independent from the concrete elements, only at the end of phase 0 the nodes of SMA elements are linked to nodes of concrete elements in order to simulate the adherence between the two materials;

- $\quad$ in phase 1, the flexural loading of the beam at environmental temperature is simulated. In this phase (time step 34), the displacement $v_{B}$ of the node $\mathrm{B}$ of the beam is gradually incremented;

- $\quad$ in phase 2, the unloading of the beam at environmental temperature is reproduced. In this phase (time step 4-5) the displacement $v_{B}$ of the node $\mathrm{B}$ of the beam is gradually reduced until the vertical reaction of the node $\mathrm{B}$ reaches zero value ;

- $\quad$ in phase 3,the heating of SMA equivalent bar is reproduced. In the time step 5-6, the node B is allowed free to perform displacements in vertical direction and a temperature of $180^{\circ} \mathrm{C}$ is imposed on SMA elements.

\begin{tabular}{cccc} 
Material & $E\left[N / \mathrm{mm}^{2}\right]$ & $v$ & $f_{y}\left[\mathrm{~N} / \mathrm{mm}^{2}\right]$ \\
Concrete & 28000 & 0.2 & 70 \\
\hline
\end{tabular}

Table 1: Mechanical proprieties of the uncracked concrete elements.

\begin{tabular}{|c|c|c|c|c|c|c|c|}
\hline Material & $\tau_{T}^{0}\left[N / m^{2}\right]$ & $G_{c \mathrm{~N}}[\mathrm{~N} / \mathrm{mm}]$ & $K_{N}\left[\mathrm{~N} / \mathrm{mm}^{3}\right]$ & $\tau_{T}^{0}\left[N / m^{2}\right]$ & $G_{c T}[N / m m]$ & $K_{T}\left[\mathrm{~N} / \mathrm{mm}^{3}\right]$ & $\mu$ \\
\hline Crack & 2 & 0.18 & 28000 & 2 & 0.18 & 28000 & 0.5 \\
\hline
\end{tabular}

Table 2: Mechanical proprieties of the interface elements (crack).

\begin{tabular}{|c|c|c|c|}
\hline \multicolumn{4}{|c|}{ Material SMA } \\
\hline$E_{A}\left[N / m^{2}\right]$ & 28000 & $\sigma_{s}^{A S,+}\left[N / m m^{2}\right]$ & 120 \\
\hline$E_{S}\left[N / m m^{2}\right]$ & 28000 & $\sigma_{f}^{A S,+}\left[\mathrm{N} / \mathrm{mm}^{2}\right]$ & 210 \\
\hline$\xi_{L}^{t}$ & 0.05 & $\sigma_{s}^{A S,-}\left[N / m^{2}\right]$ & 120 \\
\hline$\xi_{L}^{c}$ & 0.05 & $\sigma_{f}^{A S,-}\left[N / m^{2}\right]$ & 210 \\
\hline$M_{s}\left[{ }^{\circ} \mathrm{C}\right]$ & 20 & $\mathrm{C}^{A S,+}\left[\mathrm{MPa} /{ }^{\circ} \mathrm{C}\right]$ & 10 \\
\hline$M_{f}\left[{ }^{\circ} \mathrm{C}\right]$ & 5 & $C^{S A,+}\left[M P a /{ }^{\circ} C\right]$ & 10 \\
\hline$A_{s}\left[{ }^{\circ} \mathrm{C}\right]$ & 60 & $C^{A S,-}\left[\mathrm{MPa} /{ }^{\circ} \mathrm{C}\right]$ & 10 \\
\hline$A_{f}\left[{ }^{\circ} \mathrm{C}\right]$ & 75 & $C^{S A,-}\left[\mathrm{MPa} /{ }^{\circ} \mathrm{C}\right]$ & 10 \\
\hline
\end{tabular}

Table 3: Mechanical proprieties of the SMA elements.

\begin{tabular}{cccc}
\hline Material & $E\left[N / m^{2}\right]$ & $v$ & $f_{y}\left[\mathrm{~N} / \mathrm{mm}^{2}\right]$ \\
Steel & 188000 & 0.3 & 400 \\
\hline
\end{tabular}

Table 4: Mechanical proprieties of the elasto-plastic elements (steel bar). 


\begin{tabular}{|c|c|c|c|c|}
\hline \multirow[t]{2}{*}{ Phase } & \multirow[t]{2}{*}{ Time } & \multicolumn{2}{|c|}{ Displacement $[\mathrm{mm}]$} & \multirow[t]{2}{*}{ Temperature $\left[{ }^{\circ} \mathrm{C}\right]$} \\
\hline & & $w_{A}$ & $v_{B}$ & \\
\hline & 0 & 0 & - & 20 \\
\hline \multirow[t]{2}{*}{ Phase 0} & 1 & 14.5 & - & 20 \\
\hline & 2 & 12.5 & - & 20 \\
\hline \multirow{3}{*}{$\begin{array}{l}\text { Phase } 1 \text { and Phase } \\
2\end{array}$} & 3 & - & 0 & 20 \\
\hline & 4 & - & 1.5 & 20 \\
\hline & 5 & - & 0.83 & 20 \\
\hline Phase 3 & 6 & - & - & 180 \\
\hline
\end{tabular}

Table 5: Phases of the loading history.

\section{RESULTS}

hree numerical simulations are performed on the basis of different choices of the material model adopted for the concrete and the damage interface law. In particular, it is considered:

- a linear elastic model;

- a model with plastic nonlocal damaging behavior, adopting for the contact zone the uncoupled interface model (i.e the evolution of the interface and the body damage are not coupled);

- a model with plastic nonlocal damaging behavior, adopting for the contact zone the coupled interface model (i.e. the interface damage is influenced by the body damage).

In Fig. 4 the numerical results concerning the mechanical response in term of stress-strain curve of the SMA wire at midspan cross-section obtained during the phase 0 , is reported.

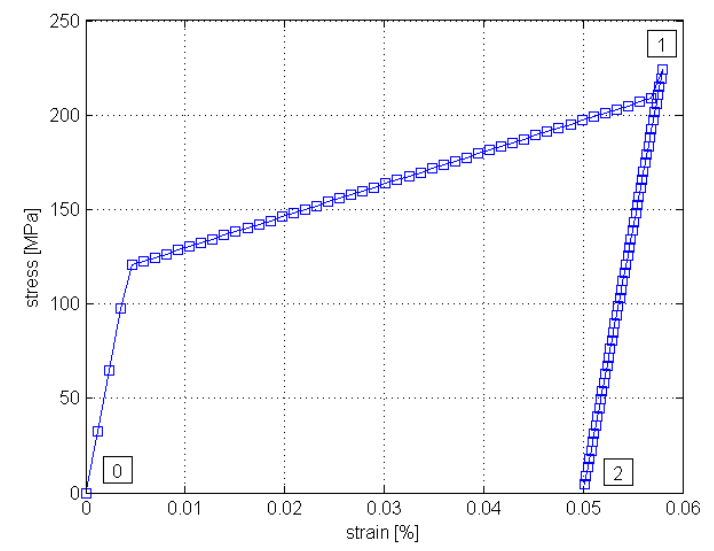

Figure 4: Prestrain of the SMA equivalent bar (phase 0).

In the graph of Fig. 5, the results of the numerical simulations, plotted in terms of reaction of the node B versus vertical displacement $v_{C}$, are compared with experimental dates provided in [1]. It can be remarked that:

- the numerical analyses are stable;

- the numerical results obtained using the elastic model approximate the experimental behavior in the worst way. In particular, the beam resistance is overestimated and the rate of the midspan displacement reached during the heating phase of the SMA bar is underestimated;

- the coupled model, compared to the uncoupled one, approximates better the experimental behavior of the smart beam. In fact, the value of the load, reached at the critical condition close to failure, is in perfect agreement with the experimental one and the rate of deflection numerically recovered (about $0.07 \mathrm{~mm}$ ), simulating the heating of the SMA equivalent bar, is in agreement with the one experimentally obtained (about $0.09 \mathrm{~mm}$ ). 


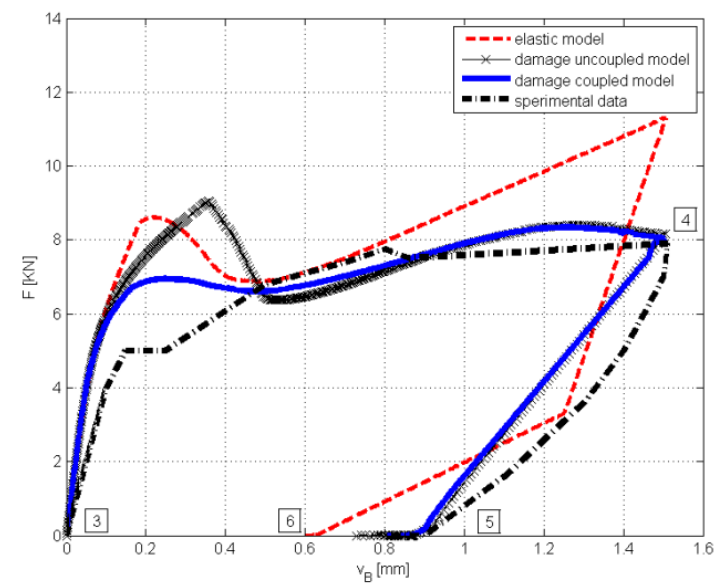

Figure 5: Experimental and numerical midspan displacement versus load graph.

\section{CONCLUSIONS}

computational strategy for the modeling of reinforced concrete beams with SMA actuators for flexural cracks
repair has been developed in the present work. The strategy consists in modeling concrete using the nonlocal
damage and plasticity model proposed in [5], flexural cracks in concrete using the interface model proposed in [4] [5], SMA wires using the model presented in [6].

This computational strategy has been used for finite element simulations of the experimental behavior of a smart concrete beam subjected to three-point bending test. Numerical results have been compared with experimental data carried out experimentally by Daghia et al. [1] to validate the model. The comparison shows the effectiveness of the proposed computational strategy to capture the experimental behavior of a smart concrete beam, both in the damaging phase and in the repairing one.

Finally, it can be emphasized that this computational strategy is an efficient tool for designing smart structural elements.

\section{REFERENCES}

[1] F. Daghia, A. Giammarruto, G. Pascale, Structural Control and Health Monitoring, 18 (2011) 908.

[2] Y. Kuang, J. Ou, Smart Materials and Structures, 17 (2008) 1-7.

[3] H. Li, Z.-q. Liu, J.-p. Ou, Smart Material and Structures, 15 (2006) 1039.

[4] S. Marfia, E. Sacco, J. Toti, Computational Mechanics, 50(3) (2012) 335.

[5] J. Toti, S. Marfia, E. Sacco, Computer Methods in applied Mechanics and engeenering, 260 (2013) 1.

[6] S. Marfia, J. N. Reddy, E. Sacco, AiAA Journal, 41(1) (2003) 100.

[7] O. C. Zienkiewicz, R. L. Taylor, The finite element method, London: Fourth ed. McGraw-Hill, (1991). 